\title{
ANÁLISE DO PROCESSO DE ADAPTAÇÃO ESTRATÉGICA DE UMA EMPRESA PRODUTORA DE CACHAÇA À LUZ DA TEORIA INSTITUCIONAL E DA VISÃO BASEADA EM RECURSOS
}

\author{
Antonio Rodrigues Neto \\ antonho.rn@hotmail.com \\ Universidade Federal de Campina Grande - Campina Grande, PB / Brasil \\ Lucia Santana de Freitas \\ luciasf@ch.ufcg.edu.br \\ Universidade Federal de Campina Grande - Campina Grande, PB / Brasil
}

\begin{abstract}
Recebido em 20/04/2010
Aprovado em 05/10/2011

Disponibilizado em 01/04/2012

Avaliado pelo sistema double blind review

Revista Eletrônica de Administração

Editor: Luís Felipe Nascimento

ISSN 1413-2311 (versão on-line)

Editada pela Escola de Administração da Universidade Federal do Rio Grande do Sul.

Periodicidade: Quadrimestral
\end{abstract}

Sistema requerido: Adobe Acrobat Reader.

\section{RESUMO}

A realização deste trabalho teve como objetivo principal conhecer o processo de adaptação estratégica da empresa Vargem Bela, produtora de cachaça no Brejo paraibano. Primeiro, identificou-se os eventos críticos ocorridos no período de 1961 a 2007 e verificou-se sob quais condições estes eventos ocorreram, para então, analisá-los sob a perspectiva da Teoria Institucional e da Visão Baseada em Recursos. Com essa finalidade, foi feita uma revisão na literatura existente sobre as referidas teorias, com ênfase nos trabalhos de DiMaggio e Powell (2005), no que diz respeito à Teoria Institucional, e Peteraf (1993) e Barney e Herterly (2007) no que se refere à Visão Baseada em Recursos. O trabalho é uma pesquisa qualitativa, descritiva e exploratória, que se deu através de um estudo de caso que teve sua sustentação metodológica baseada no trabalho de Pettigrew (1987), sobre métodos de adaptação estratégica de empresas, onde são investigados três elementos da mudança: o contexto (interno e externo), o conteúdo e o processo. A pesquisa possibilitou concluir que o processo de adaptação estratégica vivido pela empresa, apresenta características diferentes em dois períodos temporais distintos. O primeiro período, que vai de 1961 até 1986, em que a postura organizacional assumida no processo de mudança é mais proativa, foram realizadas aquisições de ativos tangíveis e intangíveis capazes de construir vantagens competitivas sustentáveis tornando a empresa mais competitiva e líder de mercado. Entretanto, no segundo período, que vai de 1986 a 2007, a postura assumida pela empresa passa a ser mais reativa, numa demonstração de inércia organizacional, passando a atuar no sentido de atender às pressões ambientais. 
Análise do processo de adaptação estratégica de uma empresa produtora de cachaça à luz da teoria institucional e da visão baseada em recursos

Palavras-chave: Setor de Cachaça, Adaptação Estratégica, Teoria Institucional, Visão Baseada em Recursos.

\title{
ANALISYS OF STRATEGIC ADAPTATION PROCESS OF A SUGGAR CANE BRANDY COMPANY PRODUCER UNDER THE LIGHT OF INSTITUTIONAL THEORY AND RESOUR-BASED VIEW
}

\begin{abstract}
The accomplishment of this work had as main goal knowing the process of strategic adaptation of Vargem Bela Company, producer of sugar cane brandy in the swamp of Paraiba. First of all, the critical events occurred during the period between 1961 to 2007 were identified, and were verified the conditions under which these events occurred, to then analyze them under the perspective of Institutional Theory and the Resource Based View. With this purpose, a review was made in the existing literature on these theories, with emphasis on the work of DiMaggio and Powell (2005), when referring to the Institutional Theory, and Peteraf (1993) and Barney and Herterly (2007) in what refers to the Resource Based View. The work is a qualitative, descriptive and exploratory, that was made through a case study that had his support methodology based on the work of Pettigrew (1987), on methods of strategic adaptation of firms, where three elements of change are investigated: the context (internal and external), content and process. The research led us to conclude that the strategic adaptation process experienced by the company, presents different characteristics in two different time periods. The first period, which runs from 1961 until 1986, in which the organizational posture assumed in the change process is more proactive, tangible and intangible assets were purchased that were able to build sustainable competitive advantages by making the company more competitive and market leader. However, in the second period, which lasts from 1986 to 2007, the posture taken by the company becomes more reactive, in a show of organizational inertia, starting to act in order to convene environmental pressures.
\end{abstract}

Keywords: Sugar Cane Brandy Sector, Strategic Adaptation, Institutional Theory, Resource based View.

\section{INTRODUÇÃO}

O setor produtivo de cachaça no Brasil está dividido em dois segmentos que se distinguem pelo processo de produção: o processo industrial, com produção em escala, por meio de modernas colunas de destilação e com sofisticados recursos de análises laboratoriais normalmente feitos pelos grandes grupos produtores; e o processo por alambique, mais artesanal, em geral feito por pequenos produtores, com recursos mais modestos. 


\section{Antonio Rodrigues Neto \& Lucia Santana de Freitas}

A produção nacional de cachaça $^{1}$, segundo dados do Ministério da Agricultura, Pecuária e Abastecimento - MAPA - é de aproximadamente 1,4 bilhões de litros, sendo a cachaça o destilado mais consumido no país e o terceiro no mundo, ocupando ainda o segundo lugar entre todas as bebidas alcoólicas, ficando atrás apenas da cerveja. As bebidas destiladas têm um consumo mundial médio per capta de 2,2 litros, e no Brasil a cachaça tem uma média de consumo por habitante de aproximadamente sete litros. A cachaça tem uma participação estimada no PIB de US\$ 500 milhões, existindo cerca de quatro mil marcas registradas no MAPA, 1.824 estabelecimentos produtores registrados no mesmo ministério, com mais de trinta mil produtores em todo o país, que geram aproximadamente 400 mil empregos diretos e indiretos (MAPA, 2007).

Segundo Instituto Brasileiro da Cachaça (IBRAC), os estados brasileiros que têm relevância na produção de cachaça são: São Paulo (44\%), Pernambuco (12\%), Ceará (12\%), Minas Gerais (8\%) e Paraíba (8\%), encontrando ainda produção significativa de cachaça nos estados do Rio Grande do Sul, Santa Catarina, Paraná, Rio de Janeiro, Espírito Santo, Goiás, Mato Grosso do Sul, Tocantins, Bahia, Alagoas e Piauí (IBRAC, 2007).

A maior parte da cachaça produzida no Brasil é destinada ao mercado interno. No ano de 2007, o Brasil exportou 9.052.453 de litros de cachaça, o que, considerando uma produção média anual de 1,4 bilhões de litros (MAPA, 2007), corresponde a apenas aproximadamente $0,6 \%$ do total produzido. A Alemanha tem sido a principal importadora em termos de quantidade, com um percentual de $22,1 \%$ do total da cachaça exportada em 2007. Já com percentuais significativos, aparecem numa ordem decrescente o Paraguai, com 11,6\%; o Uruguai, com 9,2\%; Portugal, com 8,8\%; a França, com 7,3\%; os Estados Unidos, com 7,1\%; o Chile, com 5,4\%; e a Espanha, com 4,4\%. Os demais países que importam cachaça do Brasil perfazem um total de 7,9\%.

No que se refere ao mercado internacional, considerando o período de 1997 a 2007 , houve uma queda substancial em relação à quantidade exportada - foram exportados pouco mais de 77 milhões de litros para aproximadamente nove milhões em 2007. Entretanto, conforme demonstrado na Tabela 1 e tomando como referência o valor do litro, a situação se inverte levando a uma valorização do valor do litro, passando de US\$ 0,11 em 1997, para US\$ 1,53 em 2007. 
Análise do processo de adaptação estratégica de uma empresa produtora de cachaça à luz da teoria institucional e da visão baseada em recursos

Tabela 1: Exportação de brasileira no período de 1997 a 2007.

\begin{tabular}{c|c|c|c}
\hline ANO & QT - LITRO & VALORES - U\$ & PREÇO MÉDIO - LITRO \\
\hline 1997 & 77.070 .132 & 8.361 .050 & US\$ 0,11 \\
\hline 1998 & 5.566 .046 & 6.919 .347 & US\$ 1.24 \\
\hline 1999 & 7.821 .720 & 7.398 .186 & US\$ 0.95 \\
\hline 2000 & 13.429 .284 & 8.146 .524 & US\$ 0.61 \\
\hline 2001 & 10.150 .312 & 8.452 .635 & US\$ 0.83 \\
\hline 2002 & 14.535 .046 & 8.733 .811 & US\$ 0.60 \\
\hline 2003 & 8.663 .912 & 9.016 .444 & US\$ 1.04 \\
\hline 2004 & 8.607 .150 & 11.087 .500 & US\$ 1.29 \\
\hline 2005 & 10.343 .146 & 12.528 .158 & US\$ 1.27 \\
\hline 2006 & 11.322 .568 & 14.415 .033 & US\$ 1.53 \\
\hline 2007 & 9.052 .453 & 13.838 .276 & Preço Médio do Período US\$ 0,62 \\
\hline Total & 176.561 .769 & 108.896 .964 & Desenv0l vimen \\
\hline
\end{tabular}

Fonte: Elaboração própria, a partir de dados disponíveis do Ministério do Desenvolvimento Indústria e Comércio Exterior - MDIC - aliceweb.

Cabe ressaltar que os números acima apresentados referem-se ao somatório das produções e exportações por coluna e por alambique, uma vez que a legislação nacional trata o resultado dos dois processos como se fosse um só produto.

Por outro lado, o setor em sua trajetória tem conseguido alguns avanços significativos, tais como: a) execução do Projeto de Caracterização do perfil físico-químico da cachaça pela Fundação Centro Tecnológico de Minas Gerais - CETEC - e a estruturação do primeiro grupo de análise sensorial com o apoio do Centro de Tecnologia Agrícola e Alimentar - CTAA - da Embrapa - RJ; b) realização das primeiras missões internacionais de produtores à França e à Escócia, entre 1995 e 1997; c) criação do Programa Brasileiro para o Desenvolvimento da Aguardente de Cana, Caninha ou Cachaça - PBDAC no mesmo ano de 1997, reunindo produtores de vários estados brasileiros; d) criação do primeiro Programa Setorial Integrado de Apoio à Exportação de Cachaça, da Agência de Promoção das Exportações - APEX, no ano de 1999; e) criação, em 2001, da Federação Nacional das Associações dos Produtores de Cachaça de Alambique - FENACA, com a representação de cinco estados: Paraíba, Minas Gerais, Goiás, Rio Grande do Sul e Espírito Santo; f) instalação, em 2004, da Câmara Setorial da Cadeia Produtiva da Cachaça, no âmbito do Ministério da Agricultura, Pecuária e Abastecimento; g) criação, em 2006, do Instituto Brasileiro da Cachaça - IBRAC, centrado na busca da Denominação de Origem e da Indicação Geográfica da Cachaça; h) início do Processo de Certificação da Cachaça por iniciativa do INMETRO e do SEBRAE com o apoio da FENACA e outras instituições através do PE 5b - Programa Estratégico de Fortalecimento das micro e pequenas empresas no Sistema Brasileiro de Avaliação da Conformidade; i) 


\section{Antonio Rodrigues Neto \& Lucia Santana de Freitas}

formação de equipes de análise sensorial pela FENACA, com a participação de técnicos e cientistas de 08 estados em convênio com a EMBRAPA; entre outros (ALBENAZ, 2007).

Entretanto, mesmo diante de tais avanços o setor ainda sofre, além de limitações, com a alta tributação, principalmente as empresas que produzem cachaça de alambique, tais como: predominância de micro e de pequenos produtores, baixa capacidade financeira, uso de equipamentos obsoletos e com o mercado pouco dinâmico (LIMA, 2006), concorrência desigual com produtores informais, entre outros.

O processo de mudança vivenciado pelo setor nos últimos anos pode ser explicado a partir de diferentes perspectivas teóricas. Dada a complexidade dos diferentes fatores envolvidos em tal processo, optou-se pela utilização de duas teorias: a Teoria Institucional e a Visão Baseada em Recursos. A primeira teoria permite explicar o isomorfismo imbuído no processo de mudança; e, a segunda teoria permite explicar os recursos e capacidades organizacionais e sua relação com vantagens competitivas sustentáveis. O uso conjunto de duas teorias aumenta o poder explicativo do fenômeno estudado, bem como ajuda a reduzir as limitações individuais de cada teoria.

Por fim, considerando por um lado, a importância do setor produtivo de cachaça e as mudanças vivenciadas nos últimos anos e por outro lado, a baixa quantidade de trabalhos científicos encontrados que tratem especificamente do referido setor, e ainda, que são raras as pesquisas que analisam o processo de adaptação estratégica vivenciado pelas organizações de tal setor, o presente estudo tem como objetivo conhecer o processo de adaptação estratégica da empresa Vargem Bela Agroindustrial Ltda.

Para tanto, o presente trabalho se estrutura em cinco partes: a primeira parte composta pela presente introdução, na qual se contextualizou o setor em estudo, a importância da realização do trabalho e definiu-se seu objetivo. Na segunda parte, a fundamentação teórica, procura-se abordar as duas teorias que darão suporte à pesquisa, Teoria Institucional e Visão Baseada em Recursos. Na terceira parte, os procedimentos metodológicos, nos quais se caracteriza a pesquisa e os respectivos métodos e técnicas a serem utilizados durante a realização do trabalho. Na quarta parte, procede-se a apresentação e análise dos resultados, sendo esta a parte mais extensa do trabalho, dado que o intervalo estudado foi de 46 anos e, por isso, há uma quantidade significativa de informações a serem trabalhadas. Na quinta parte, as considerações finais da pesquisa, na qual se faz conhecer aspectos relevantes que 
Análise do processo de adaptação estratégica de uma empresa produtora de cachaça à luz da teoria institucional e da visão baseada em recursos

marcaram e caracterizaram os diferentes períodos do processo de adaptação estratégica vivenciado pela empresa durante o período estudado.

\section{FUNDAMENTAÇÃO TEÓRICA}

$\mathrm{Na}$ literatura sobre estratégia, independente da corrente teórica e dos diferentes conceitos encontrados sobre o que é estratégia ou como estas são formuladas, a compreensão da relação entre empresa e ambiente externo, permanece imprescindível. A necessidade da empresa se adaptar às demandas ambientais, seja respondendo as ameaças, seja criando oportunidades, continua sendo a pedra fundamental nos estudos em estratégia.

O processo de adaptação estratégica organizacional pode ser explicado por diferentes teorias, as quais podem partir de diferentes pressupostos sobre as implicações do ambiente sobre tal processo, variando em um contínuo com extremos; de um lado, o determinismo ambiental, do outro, a escolha estratégica ou voluntarismo. No determinismo ambiental, o ambiente aparece como um grande imperativo sobre as organizações, impondo seu processo de seleção natural, estas no máximo podem reagir, por algum tempo, tendendo a desaparecer. Enquanto que no voluntarismo, embora reconhecendo a força impositiva do ambiente, as organizações não apenas reagem, mas também podem vir a se impor e modificar as forças ambientais, escolhendo estratégias e assumindo uma postura mais proativa.

Neste estudo, tomaremos como base duas teorias: a Teoria Institucional, relacionada ao determinismo ambiental e a abordagem da Visão Baseada em Recursos, relacionada ao voluntarismo organizacional.

\subsection{A Teoria Institucional}

Hall e Taylor (2003) afirmam que há uma tendência geral de as teorias do institucionalismo definirem instituição como sendo “... os procedimentos, protocolos, normas e convenções oficiais e oficiosas inerentes à estrutura organizacional da comunidade política ou da economia política” e que aí estão incluídos desde “... regras de uma ordem constitucional ou dos procedimentos habituais de funcionamento de uma organização até as convenções que governam o comportamento dos sindicatos ou as relações entre bancos e empresas".

Os mesmos autores (2003) ao tratarem do Institucionalismo Sociológico, ramo do Neo-Institucionalismo que se origina da Teoria das Organizações, afirmam que estas 
Antonio Rodrigues Neto \& Lucia Santana de Freitas

assumem formato de instituições não apenas por serem mais eficazes para o cumprimento das tarefas, mas também em virtude de práticas culturais semelhantes aos mitos e às cerimônias de muitas sociedades culturais. Caldas e Fachin (2005) afirmam que os textos sobre homogeneidade e isomorfismo institucional de DiMaggio e Powell mostram-se como os principais sustentáculos do neo-institucionalismo.

DiMaggio e Powell (2005) questionam a existência de variações em termos de estrutura e comportamento organizacional concordando apenas parcialmente com Hannan e Freeman (1977), que afirmam existir diversidade de organizações. Acreditam os primeiros autores que apenas na fase inicial do surgimento de um campo organizacional as formas de administrar sejam diferentes, havendo uma tendência muito forte rumo à homogeneização, à medida que esta amadurece. Os autores explicam essa homogeneidade através do conceito de Isomorfismo, segundo o qual um processo de restrição força uma unidade organizacional a assemelhar-se a outras que, no mesmo campo, enfrentam as mesmas condições ambientais.

O Isomorfismo Institucional descreve, como de maneira progressiva, as organizações que convergem para uma tendência, ao imitarem umas às outras. Essa convergência, imposta por pressões, tanto externas quanto internas, sob a forma de normas sociais; ou pressões por conformidade, explicam, segundo os autores, a afirmativa segundo a qual a competição entre as organizações não é somente por recursos escassos e clientes, mas também por poder político e legitimidade institucional, além de adequação tanto social quanto econômica.

As mudanças organizacionais isomórficas são explicadas por DiMaggio e Powell (2005) através de três mecanismos: o isomorfismo coercitivo, no qual as mudanças estratégicas são consequências tanto de pressões formais quanto de expectativas culturais da sociedade; o isomorfismo mimético, pelo qual as estratégias adotadas têm origem nas incertezas do ambiente, incompreensão de tecnologias organizacionais e quando há ambiguidade de metas; e o isomorfismo normativo, que explica as decisões estratégicas como sendo resultado da profissionalização em que categorias de profissionais lutam para conseguir melhorias nas condições e métodos de trabalho que realizam.

\subsection{A Visão Baseada em Recursos}

A expressão Visão Baseada em Recursos (VBR), no original em inglês "The Resource-based View of the Firm", foi criada por Wernefelt (1984) conforme afirmam Barney e Hersterly (2007) com base no trabalho inicial de Penrose (2006), o qual atesta que 
Análise do processo de adaptação estratégica de uma empresa produtora de cachaça à luz da teoria institucional e da visão baseada em recursos

muito além de uma entidade administrativa, a firma constitui-se em "um conjunto de recursos produtivos, cuja disposição entre diversos usos e através do tempo é determinada por decisões administrativas”. A autora percebe ainda que os serviços que os recursos podem prestar, e não os recursos em si, constituem-se nos insumos do processo produtivo da empresa, pela sua possibilidade de uso para fins diversos por combinação com outros recursos e modos diferentes de utilização.

Barney e Hesterly (2007) definem recursos como os itens passíveis de controle por parte da empresa e que possibilitam a obtenção de Vantagem Competitiva Sustentável (VCS) por serem valiosos, raros, difíceis de imitar e de difícil substituição.

A evolução da teoria da VBR mostra também que, além dos recursos tangíveis e intangíveis, a empresa pode controlar as capacidades dinâmicas e as competências essenciais apresentam-se como fonte de VCS.

O conceito de capacidades dinâmicas, conforme Sanchez et al (1996) amplia o entendimento da VBR como uma coleção de estoques e fluxos pela explícita incorporação de cognições gerenciais que influenciam na decisão dos tipos de produtos específicos que a empresa deverá adquirir; da habilidade de coordenação dos gerentes no desdobramento e na administração do fluxo de recursos; e da habilidade dos gerentes para gerenciar o conhecimento no processo de gerar competências. O termo 'dinâmico', segundo Teece et al (1997), refere-se à capacidade de renovar competências bem como adquirir congruência com o ambiente de negócios em mudança.

King et al (2002) propõem um modelo de identificação e avaliação de competências organizacionais através do qual é possível, por parte dos gerentes, ver de maneira adequada a força ou as vulnerabilidades que têm as competências existentes na empresa, analisando-as em seu caráter tácito no que se refere à resistência, à codificação e divulgação; a sua robustez, no sentido da durabilidade no tempo frente às turbulências ambientais; a fixação, referente a possibilidade de ser transferida para a concorrência e; no consenso, que diz respeito à importância dada às competências implicando em maior coerência nas tomadas de decisões sobre o desenvolvimento de fortalecimento destas.

Peteraf (1993) sugere que na busca por recursos e competências que possam gerar VCS, estes devem apresentar as seguintes condições: condição de heterogeneidade, na qual recursos que atendem aos preceitos econômicos da escassez são denominados raros ou superiores e cuja oferta no mercado é limitada, o que eleva seu custo e possibilita a quem os 
Antonio Rodrigues Neto \& Lucia Santana de Freitas

possuem menores custos médios e lucros extraordinários; limites à competição ex-ante, referente à aquisição ou desenvolvimento por parte da empresa de recursos que virão a ser raros ou superiores, isto possibilitado pelo fato desta possuir informações privilegiadas acerca das condições do mercado; limites à competição ex-post, que diz que a empresa ao possuir um recurso valioso deve preservá-lo por meio das condições de imperfeita imitabilidade e imperfeita substituição e; imperfeita mobilidade, quando o produto possui especificidade com a empresa, ocorrendo também quando utilizado juntamente com outros recursos, neste caso são chamados de co-especializados.

Barney e Hersterly (2007) propõem um modelo para análise dos recursos e capacidades na busca pelo potencial de VCS de cada um. Para tal, segundo os autores, o recurso ou capacidade deve ter valor para possibilitar a exploração de uma oportunidade ou neutralizar uma ameaça surgida no ambiente; deve ser raro quanto aos concorrentes possuílos ou virem a possuí-los; deve ser imperfeitamente imitável, no que se refere à possibilidade das empresas, que não o possui, enfrentarem dificuldade em custos para adquirilo ou desenvolvê-lo; e ter condição de organização, que diz respeito ao fato de a empresa estar organizada administrativamente para explorar ao máximo seus recursos e capacidades valiosas, raras e de imperfeita imitabilidade.

Após uma breve revisão da literatura sobre as teorias acima mencionadas, pode-se perceber que o processo de adaptação estratégica de uma organização pode ser analisado segundo estas duas perspectivas. Mesmo considerando que essas partem de diferentes pressupostos teóricos acerca das implicações do ambiente sobre as organizações, ambas não se apresentam mutuamente excludentes, ao contrário, a utilização conjunta de tais teorias leva a possibilidade de, por um lado, reduzir as limitações individuais de cada teoria e, por outro lado, aumentar o poder explicativo do processo de adequação estratégica das organizações face à dinamicidade e natureza multifacetada dos ambientes em que estas se inserem.

\section{PROCEDIMENTOS METODOLÓGICOS}

O trabalho desenvolveu-se por meio de uma pesquisa qualitativa a qual, segundo Neves (1996), constitui-se de um conjunto de várias técnicas interpretativas que objetivam a descrição e a decodificação de fenômenos e sistemas em seus diversos componentes. Segundo Godoy (1996), ao implementar uma pesquisa qualitativa, o pesquisador envolve-se diretamente com a situação estudada na busca por dados que descrevam pessoas, lugares e 
Análise do processo de adaptação estratégica de uma empresa produtora de cachaça à luz da teoria institucional e da visão baseada em recursos

processos e que permitam o entendimento da situação estudada pela visão que têm os sujeitos abaixo.

A investigação faz a análise do processo de adaptação estratégica de uma empresa no decorrer de 46 anos de sua existência e foi realizada por meio de um estudo de caso que, segundo Yin (2001), é a metodologia utilizada quando se faz necessário responder à questões do tipo "como" e "por quê" da ocorrência de certos fenômenos.

O caso escolhido e estudado corresponde a empresa Vargem Bela Agroindustrial Ltda. - nome fictício - com suas atividades produtivas realizadas na região do Brejo paraibano, e o período analisado vai de 1961 a 2007, correspondendo a aproximadamente cinco décadas. Em cada década procurou-se identificar os fatos históricos mais importantes, os quais foram denominados de eventos críticos, considerados fortes impulsionadores do processo de mudança. Neste estudo, tomou-se como base a perspectiva dos gestores envolvidos no referido processo.

Quanto aos dados, utilizou-se nesta pesquisa dados primários e secundários. Os dados primários foram obtidos por meio de seis entrevistas em profundidade, realizadas no período de 14 de janeiro a 02 de março de 2008 com os dois gestores e proprietários - realizadas separadamente, ressaltando que ambos compõem as duas gerações que estiveram na gestão da empresa durante o período estudado. Quanto aos dados secundários, foram utilizadas informações sobre estudos científicos já realizados sobre adaptação estratégica e informações gerais sobre o setor produtivo de cachaça. Tais informações foram obtidas em livros, revistas eletrônicas, jornais, dissertações de mestrado, artigos publicados, arquivos da empresa, email, sites da internet, etc.

Em relação ao tratamento dos dados, foi utilizado o método proposto por Pettigrew (1987) tendo em vista ser uma metodologia abundantemente utilizada na literatura e em estudos que tratam de adaptação ou mudança estratégica (ROSSETTO et al, 1996; MONTEIRO e CARDOSO, 2002; SERRALHEIRO, 2004; COTA, 2006; ALPERSTED et al, 2006). Segundo Pettigrew (1987), o ponto de partida da análise de mudança estratégica de uma organização é a noção de que a formulação do conteúdo de uma nova estratégia inevitavelmente implica em gerenciar seu contexto e seu processo. Nesse sentido, o conteúdo refere-se à área específica de transformação sobre investigação. Assim, a empresa pode estar procurando mudar a sua tecnologia, produtos, posicionamento geográfico, potencial humano, ou até mesmo a cultura corporativa. Quanto ao contexto, o autor afirma 
Antonio Rodrigues Neto \& Lucia Santana de Freitas

que deve-se analisá-lo interna e externamente, referindo o contexto externo aos ambientes social, econômico, político e competitivo onde a empresa atua e, o contexto interno à estrutura, cultura corporativa e contexto político intrínseco à firma. Enquanto que no processo, a mudança diz respeito às ações, reações e interações das diferentes partes interessadas em mudar o estado atual da firma para um estado futuro.

Portanto, de acordo com Pettigrew (1987), ao se fazer o estudo do processo de adaptação estratégica de uma organização, deve ser levada em consideração a interação entre três elementos da mudança: o conteúdo relacionado à questão ‘o que?'; o contexto, interno e externo, relacionado à questão 'por quê?' e; o processo, relacionado à questão ‘como?' .

\section{APRESENTAÇÃO E ANÁLISE DOS RESULTADOS}

\subsection{Caracterização do Setor Produtivo de Cachaça}

Essa área de atividade se caracteriza por ser formada por dois produtos que se distinguem pelo processo de produção: a caninha industrial, cujo processo é realizado em colunas de destilação de maneira contínua, feito pelas grandes padronizadoras e a cachaça $\operatorname{artesanal}^{2}$, cujo processo se dá por bateladas simples, isto é, determinada quantidade de cana que é moída cujo caldo sofre o processo de fermentação.

O processo de produção de cachaça inicia-se com a moagem da cana-de-açúcar para obtenção do caldo, o qual deve ser filtrado e preparado para a fermentação. É na etapa da fermentação, que acontece em recipientes chamados dornas, que, por ação das leveduras, os açúcares do caldo de cana se transformam principalmente no vinho a ser destilado. Até esta etapa - a da obtenção do vinho -, o processo é semelhante (mas não igual) tanto para o processo industrial quanto para o processo artesanal. Na etapa da destilação, para obtenção da aguardente, encontra-se a verdadeira diferença entre aguardente de cana e cachaça.

A destilação no processo industrial é feita pelo método de coluna, feita de maneira ininterrupta em colunas de aço inoxidável, onde entra o mosto fermentado e sai a aguardente de cana-de-açúcar. O sistema de colunas contém válvulas que permitem o escape de gases impróprios ao consumo humano.

No processo dito artesanal, feito por batelada em alambiques de cobre, esses são abastecidos com o vinho resultante da fermentação que por ação de fogo direto ou por vapor de caldeira, evapora. Neste ponto, os vapores menos voláteis voltam ao estado líquido e os 
Análise do processo de adaptação estratégica de uma empresa produtora de cachaça à luz da teoria institucional e da visão baseada em recursos

álcoois, por serem mais voláteis, seguem por uma serpentina que resfriada faz o vapor tornar ao estado líquido já como cachaça. A primeira saída constituída dos primeiros 10\% produzidos constitui-se a "cabeça" e são impróprios para consumo em virtude do alto teor alcoólico. A segunda saída é o "coração", formado por cerca de $80 \%$ do produto e é a cachaça ideal que pode ser consumida. A terceira saída, os 10\% restantes, é chamada "cauda" ou "caxixi” e também é descartada em virtude do baixo teor alcoólico.

O processo produtivo se apresenta de maneira diferente entre estes dois tipos de produtos, bem como os custos de produção inerentes a tais processos. Segundo Verdi (2006), uma análise do custo de produção de cada um dos segmentos pode variar entre R $\$ 0,46$ e R\$ 0,48 , para uma garrafa elaborada industrialmente, e de $\mathrm{R} \$ 1,20$ para a garrafa produzida artesanalmente. De acordo com Silva et al (2007) a cachaça artesanal, quando produzido sob padrões de qualidade superiores, apresenta um maior grau de pureza frente a outros destilados em virtude do uso de fermentos naturais, a ausência de aditivos e o aproveitamento da parte destilada denominada coração.

Quanto à capacidade produtiva, segundo o Instituto Brasileiro da Cachaça - IBRAC (2007), o segmento de cachaça de alambique tem uma capacidade instalada de 1,2 bilhões de litros. Conforme Albernaz (2007), segundo dados da Federação Nacional das Associações de Produtores de Cachaça de Alambique (FENACA), este segmento apresenta uma produção nacional com números que se aproximam de 500 milhões de litros, sendo metade deste número produzida em Minas Gerais, obtendo um crescimento da ordem de $5 \%$ ao ano (VERDI, 2006). O segmento gera cerca de $90 \%$ dos empregos do setor e $65 \%$ dos seus produtores enquadram-se nos critérios da agricultura familiar. Grande parte da produção de cachaça de alambique acontece na região do semi-árido.

O segmento produtor de cachaça de alambique é constituído de três blocos: o primeiro bloco, com maior quantidade de participantes entre as empresas registradas no MAPA, utiliza modernas técnicas de produção e de gestão do negócio, sendo o principal responsável pela melhoria da qualidade da cachaça, pela sofisticação e melhoria de padrão da embalagem. $\mathrm{O}$ segundo bloco, formado pelas empresas cooperativadas do sistema Organização das Cooperativas do Brasil - OCB, ultrapassa as barreiras que limitam a escala e padrão dos pequenos produtores. O terceiro bloco, constituído por cerca de $65 \%$ do total de produtores, articulam-se através da União Nacional das Cooperativas da Agricultura Familiar Economia Solidária - UNICAFES, não tendo ainda presença marcante no mercado nacional. 


\section{Antonio Rodrigues Neto \& Lucia Santana de Freitas}

A produção de cachaça no Estado da Paraíba está localizada na Região do Brejo, mas com produção significativa na Zona da Mata Paraibana, produzida em aproximadamente 60 engenhos e há por volta de 30 marcas registradas (CAVALCANTI, 2007).

A cachaça artesanal da Paraíba tem liderança na Região Nordeste e tem ainda importância nacional em virtude da sua qualidade, apresentando três marcas Paraibanas: Cigana, Volúpia e Bandeira Branca, selecionadas pela Agência de Promoção à Exportação para compor um grupo de cinco, que representaram o Brasil em uma Rodada de Negócios em Lisboa no primeiro semestre do corrente ano (FORMIGA, 2007).

As cachaças da Paraíba mais aceitas pelos mercados interno e externo são: Volúpia, premiada pela revista Playboy em 2003; Serra Preta, que levou a medalha de ouro no ano passado pelo Instituto Internacional Hyatt Cachaça Awards; Matuta, Olho D'água, Tucuruvi, Serra de Areia, Cigana, Tambaba, Caruçu, Triunfo e Bandeira (PATRIOTA, 2006).

No período de 1997 a 2007 não houve constância nas exportações de cachaça da Paraíba (como mostra a Tabela 2), principalmente nos anos de 1998, 2000 e 2007, além de terem sido pouco significativas no que se refere à quantidade como vê-se nos anos de 2002, 2004 e 2006.

Mesmo diante do reconhecimento do Estado como importante produtor de cachaça de alambique e se dispor de marcas conhecidas, as exportações ainda apresentam-se baixas, sendo a maior parte da produção destinada ao mercado interno, seguindo o mesmo comportamento do setor em nível nacional. 
Análise do processo de adaptação estratégica de uma empresa produtora de cachaça à luz da teoria institucional e da visão baseada em recursos

Tabela 2: Exportação de Cachaça pelo Estado da Paraíba no período de 1996 a 2007.

\begin{tabular}{r|r|r|r}
\hline ANO & \multicolumn{2}{|c|}{ VALOR } & \multicolumn{2}{c}{$\begin{array}{c}\text { QUANTIDADE } \\
\text { EM LITROS }\end{array}$} \\
\hline 1996 & EM US\$ & 11.800 & $\begin{array}{c}\text { PREÇO MÉDIO } \\
\text { EM US\$ }\end{array}$ \\
\hline 1997 & 16.830 & 1.405 & 1,43 \\
\hline 1998 & 33.720 & 0 & 24 \\
\hline 1999 & 23.670 & 17.974 & 0 \\
\hline 2000 & 0 & 0 & 0 \\
\hline 2001 & 38.044 & 1.839 & 20,69 \\
\hline 2002 & 17.528 & 924 & 18,97 \\
\hline 2003 & 16.675 & 12.180 & 1,37 \\
\hline 2004 & 1.746 & 227 & 7,69 \\
\hline 2005 & 36.302 & 20.946 & 1,77 \\
\hline 2006 & 2.345 & 294 & 7,98 \\
\hline 2007 & 0 & 0 & 0 \\
\hline & VLR TOTAL: 186.860 & QUANT. TOTAL: 67.589 & \\
\hline
\end{tabular}

Fonte: elaboração própria, a partir de dados do MDIC - aliceweb (2008).

\subsection{A adaptação estratégica da empresa Vargem Bela}

A empresa Vargem Bela Agroindustrial Ltda. tem sua sede no engenho de mesmo nome situado na região do Brejo paraibano e tem como proprietários os senhores Armando Ferreira e Armando Ferreira Júnior, pai e filho, respectivamente. Como foi registrado na metodologia e como forma de resguardar a empresa, todos os nomes (da empresa, pessoas e produtos) aqui utilizados são fictícios.

A diversificação relacionada de rapadura, mel de engenho e cachaça é o que caracteriza a produção atual da empresa, com ênfase na produção de cachaça. No que se refere a esta última, a empresa produz por safra uma média de 250.000 litros de cachaça do tipo industrial, contra uma média de 150.000 litros do tipo artesanal, possuindo capacidade instalada para 400.000 litros e 250.000 litros para os dois tipos acima, respectivamente.

A família do Senhor Armando produz cachaça na região do Brejo Paraibano desde os idos de 1944, em um negócio que continua há três gerações. Nessa época, os negócios eram tocados pela primeira geração, na pessoa do Senhor Juvenal, pai do Senhor Armando e avô do Senhor Armando Júnior. O Senhor Armando estudava em João Pessoa e de repente deixou o colégio e voltou para casa. O pai dele decidiu comprar um alambique para que ele pudesse se ocupar e ganhar o seu próprio dinheiro. Nessa atividade, a matéria prima utilizada era o esborro, subproduto até então descartado por não haver como aproveitá-lo, resultante da 
Antonio Rodrigues Neto \& Lucia Santana de Freitas

produção de rapadura e mel que naquela época eram os únicos produtos do Engenho Vargem Bela.

\subsubsection{A década de 60 - A Visão Empreendedora como Motor do Negócio de Cachaça}

Os gestores da empresa decidiram no ano de 1961 produzir cachaça a partir, não mais do esborro da rapadura, mas diretamente da cana-de-açúcar. Segundo Armando Júnior, tal decisão deveu-se ao fato de que a lucratividade da cachaça apresentava-se superior à da rapadura e do mel.

Evento crítico 1 - Adoção de Cana-de-açúcar como Matéria-prima de Produção de Cachaça: A percepção por parte do proprietário de que produzir cachaça era uma atividade mais lucrativa do que as que já desenvolvia e a adoção de uma nova matéria-prima como recurso produtor, caracteriza-se como uma procura por legitimidade e exploração de uma oportunidade percebida junto ao ambiente, uma vez que a cana-de-açúcar era o insumo mais utilizado pela grande maioria dos produtores de cachaça daquela época.

Assim colocado, percebe-se que a legitimidade buscada tem característica do Isomorfismo Institucional e que se deu através do isomorfismo mimético (DIMAGGIO e POWELL, 2005). Entretanto, é fácil perceber que o evento tem também relação com a Visão Baseada em Recursos ao responder positivamente à questão do valor, pelo fato de ter possibilitado aproveitar uma oportunidade de mercado e o aumento da lucratividade (BARNEY e HESTERLY, 2007).

\subsubsection{A década de 70 - A Virada da Aquisição do Conhecimento e a Inovação Pioneira no Processo de Fermentação}

De 1944 até o ano de 1974, ou seja, durante 30 anos a empresa produziu cachaça com pouco conhecimento sobre o assunto, principalmente na etapa de fermentação. Além disso, nessas três décadas as tentativas, erros e acertos proporcionaram a apreensão de certo conhecimento empírico o qual, quando posto em prática, levava a uma média de acerto entre $70 \%$ e $80 \%$. Havia, no entanto, muita perda de matéria prima, de trabalho e de recursos financeiros em virtude da infecção por bactérias na etapa de fermentação, como relata senhor Armando:

\footnotetext{
"No mês de dezembro de 1974, em um dia em que nada deu certo e que eu já havia desistido de produzir cachaça, mandado virar as dornas de fermentação e decidido vender a safra de cana para as usinas produtoras de açúcar, apareceu em minha casa uma pessoa que dizia se chamar Miguel Falcone ${ }^{3}$,era professor USP e estava em
} 
Análise do processo de adaptação estratégica de uma empresa produtora de cachaça à luz da teoria institucional e da visão baseada em recursos

Campina Grande em visita a um ex-aluno seu, a quem pediu que lhe apresentasse alguém que produzisse cachaça. Em princípio eu nem quis recebê-lo de tanta raiva que estava pelo problema da cachaça. Mas fui aconselhado pela minha esposa a ouvir o que o homem tinha dizer. Resolvi atendê-lo e lhe disse que o que ele sabia de cachaça era coisa de livros, que eu já tinha mais de quinze anos nesse negócio e que estava desistindo naquele dia, pois a coisa não estava dando certo. Ele então me disse que estava ali para ajudar e me convenceu a tentar. Pediu que trouxesse uma dorna limpa, botou no alpendre da minha casa, preparou um pé-de-cuba ${ }^{4}$ com fermento que trazia consigo em uma pipeta, encheu com caldo de cana e naquele dia não foi embora, dormiu na minha casa. Ele dormiu, eu não. De madrugada, resolvi olhar e acordei todo mundo aos gritos para ver a fermentação. Antes, agente esperava até dez dias e em grande parte das vezes, não acontecia e se perdia material. Agora estava acontecendo em menos de 24 horas. Ele me aconselhou a ir dormir e no outro dia mandou limpar as dornas, dividiu aquele pé-de-cuba inicial e mandou moer cana".

Mesmo antes da visita do Professor Miguel Falcone, a empresa já era a maior produtora de cachaça da região do Brejo paraibano, produzindo em torno de 2.000 litros/dia e, com o domínio da técnica de fermentação, a empresa passou a produzir 3000 litros/dia, tendo demanda de mercado para aproximadamente 5000 litros/dia.

Neste momento histórico, a produção tinha como principal gargalo as limitações do equipamento que possuía, posto que a técnica de fermentação estava dominada, não havendo mais a perda de matéria prima mas o equipamento era o mesmo de antes, conforme o relato de Armando Júnior:

\begin{abstract}
"O aumento na produção deveu-se ao ganho de tempo no processo de fermentação, mas o equipamento que tínhamos ainda era o mesmo. A técnica de fermentação estava dominada, mas ficamos presos às nossas limitações. Precisávamos fazer alguma coisa para atender a demanda que se mostrava no ambiente".
\end{abstract}

Assim, no ano de 1975, a empresa visando atender à demanda bem como aumentar sua capacidade produtiva, passou a adquirir terras para aumentar a área plantada. Conforme relata o proprietário: "Quem tivesse terras aqui por perto e quisesse vender, eu comprava".

Em 1979, o Senhor Armando viajou ao estado de São Paulo, onde na cidade de Piracicaba adquiriu uma destilaria que eles chamam de ferragem, ao preço de um milhão e trezentos mil cruzeiros, a qual veio de São Paulo em oito caminhões e teve sua instalação terminada em 1981, quando começou a funcionar, alavancando a produção para 5.000 litros/dia.

Evento crítico 2: A Aquisição do Conhecimento (1974): A apreensão da técnica de fermentação tornou a única empresa a dispor deste know how na Paraíba, o que na perspectiva de King et al (2002) torna este conhecimento uma competência essencial, possuidor de 
Antonio Rodrigues Neto \& Lucia Santana de Freitas

características tácitas por ser resistente à codificação e à divulgação, além de também possuir características de robustez pela sua grande duração no tempo.

Considerando que naquele momento histórico e durante algo em torno de treze anos, o Senhor Armando era o único detentor desta competência no universo de produtores de cachaça da Paraíba, tal competência atendia ao princípio econômico da escassez, o que a caracterizava como um recurso raro ou superior, possuindo assim, conforme Peteraf (1993), condição de heterogeneidade e ainda conforme a mesma autora, detendo a condição de limites à competição ex-post pelo mecanismo de ambiguidade causal, uma vez que a concorrência não conseguia recriar com a mesma eficiência ou até identificar a competência valiosa.

Seguindo o pensamento de Barney e Hesterly (2007) fica claro que esta competência responde positivamente a questão do valor e da imitabilidade, sendo neste último caso imperfeitamente imitável pelo mecanismo de ambiguidade causal.

Evento crítico 3 - Aquisição de Terras (1975): O empreendedorismo dos proprietários aliado à proatividade lhes permitiu perceber a necessidade de aquisição de ativos; terras para, em princípio, tornarem-se cada vez mais independente em relação à matéria-prima pelo aumento da área plantada, uma vez que ainda havia a necessidade de comprar cana-de-açúcar de outros produtores. Outro objetivo da aquisição de terras decorreu da percepção de que a demanda pela cachaça era crescente naquele momento. Tal voluntarismo relaciona-se à questão do valor (BARNEY e HESTERLY, 2007), uma vez que responde positivamente a referida questão, pois o recurso adquirido proporcionou Vantagem Competitiva em virtude de possibilitar explorar uma oportunidade surgida no ambiente.

Evento Crítico 4 - Aquisição de uma Destilaria (1979): Esse evento demonstra mais uma vez o espírito empreendedor dos proprietários pela visão da crescente demanda mostrada pelo mercado, além de solucionar parcialmente o problema dos gargalos e restrições existentes no processo, uma vez que se ganhou tempo na fermentação embora a moagem não atendesse à demanda daquele processo.

A análise teórica deste evento à luz da teoria da VBR pelo modelo VRIO de Barney e Hesterly (2007), mostra que o mesmo atende de maneira positiva à questão do valor, já que possibilitou a exploração da demanda do ambiente por mais cachaça, incrementando assim a lucratividade ao compor o feixe de recursos da empresa, caracterizando-se assim, como uma fonte de VCS. 
Análise do processo de adaptação estratégica de uma empresa produtora de cachaça à luz da teoria institucional e da visão baseada em recursos

\subsubsection{A década de 80 - A Criação da Vargem Bela Agroindustrial Ltda., o Crescimento e o Surgimento da Concorrência}

No ano de 1982, ocorreu a legalização da Vargem Bela Agroindustrial Ltda., com sede no Engenho de mesmo nome, no brejo paraibano. A legalização da empresa teve como objetivo a expansão das vendas, bem como o atendimento à demanda das grandes padronizadoras como Ypioca, Caranguejo e Pitú.

Nessa época, mais precisamente em 1983, o Senhor Armando viajou a São Paulo mais uma vez, sendo, nesta oportunidade, para comprar uma coluna de destilação a fim de que, com a instalação e funcionamento desta, pudesse eliminar as restrições na produção causadas pelas limitações de equipamentos.

Conforme relatam os proprietários: "Esse foi o tempo que mais ganhamos dinheiro. Além de vender para as engarrafadoras, vendíamos também muita cachaça avulsa. O pátio do engenho amanhecia o dia apinhado de gente em jumentos, carroças e Jipes. Tinha dia que só almoçávamos às três horas da tarde".

Na região do município de Areia, no Brejo paraibano, havia um engenho que estava à venda há muito tempo. As pessoas tinham medo de comprá-lo porque estava abandonado, pertencia a herdeiros e havia muitos ex-funcionários morando em suas terras. Diante disso Armando Júnior faz o seguinte relato:

\footnotetext{
"Em 1986, papai comprou o Engenho Varginha. Reunimos os antigos funcionários que ficaram apreensivos e disseram que só sairiam dali à força e informamos que íamos revitalizá-lo, que quem quisesse poderia trabalhar conosco e continuar morando onde já morava e quem não quisesse, nós indenizaríamos. E assim foi feito. Recuperamos a caldeira, fizemos à manutenção da moenda e do motor a vapor e pusemos para funcionar".
}

Esta aquisição teve como objetivo em princípio aumentar a área plantada de cana de açúcar, uma vez que ainda se comprava cana de outros produtores para atender a demanda por cachaça.

Nessa época, o conhecimento técnico pleno do processo produtivo já estava consolidado, bem como o crescimento em ativos e em vendas. Mas foi também nesta época que as vendas sofreram um abalo pelo surgimento dos primeiros concorrentes de peso, também detentores do conhecimento sobre fermentação. Relata Armando Júnior que “Em 1988, um proprietário de terras vizinhas às nossas começou a produzir cachaça" e, segundo relata o Senhor Armando, "Ele nos visitava quase todos os dias e passava muito tempo 
Antonio Rodrigues Neto \& Lucia Santana de Freitas

observando o nosso processo". Além disso, diz Armando Júnior: "passamos a sofrer a concorrência das destilarias da Zona da Mata pernambucana”.

Evento crítico 5 - A Legalização da Empresa Vargem Bela Agroindustrial Ltda. (1982): Este evento vem atender a uma imposição legal que obriga as empresas a explorarem atividades de maneira regulamentada. Assim, a ocorrência tem características de busca por legitimidade conforme a Teoria Institucional, caracterizando-se, segundo a tipologia de DiMaggio e Powell (2005), como Isomorfismo Coercitivo. Entretanto, o fato de ter passado a vender às grandes padronizadoras significou a exploração de uma oportunidade surgida no ambiente, além de ter aumentado a lucratividade da empresa, tornando-a mais visível a outros clientes, o que segundo a Teoria da Visão Baseada em Recursos na perspectiva de Barney e Hesterly (2007), responde positivamente à questão do valor.

Evento crítico 6 - Aquisição de uma Coluna de Destilação (1983): A aquisição deste ativo visou suprir uma deficiência no processo produtivo, uma vez que a ferragem adquirida em 1979 apenas aumentou a capacidade de moagem sem, no entanto, ter alterado a capacidade de destilação. O funcionamento do novo equipamento proporcionou aumento na produção, vendas e lucratividade.

A análise teórica deste evento mostra uma relação do mesmo com a teoria da Visão Baseada em Recursos, na qual, na visão de Barney e Hesterly (2007), proporcionou à empresa a possibilidade de atender a demanda do ambiente pelo seu produto, o que responde de modo positivo à questão do valor proposta pelos autores em seu modelo VRIO. Por outro lado, tal fato pode também ser visto como uma adaptação da Teoria Institucional por meio do mecanismo de isomorfismo mimético proposto por DiMaggio e Powell (2003), posto que o uso de coluna de destilação na produção de cachaça já ocorria há muito tempo em outras regiões e estados do país.

Evento Crítico 7 - Aquisição do Engenho Varginha (1986): A aquisição desse ativo, além de possibilitar suprir a deficiência que ainda havia em termos de matéria prima, uma vez que proporcionou auto-suficiência no que se refere ao insumo cana-de-açúcar, significou também acrescentar ao patrimônio da empresa uma estrutura quase pronta, inclusive apresentando recursos humanos com experiência na área.

A decisão por adquirir o Engenho Varginha reveste-se de características da Teoria VBR por oferecer Vantagem Competitiva Sustentável, dentro do modelo de Peteraf (1993), pela condição de Limites à Competição $\boldsymbol{E} \boldsymbol{x}$-post, uma vez que este é um recurso raro que não 
Análise do processo de adaptação estratégica de uma empresa produtora de cachaça à luz da teoria institucional e da visão baseada em recursos

pode ser adquirido pela concorrência, considerando que este era o único engenho disponível para venda na região. Ainda dentro da perspectiva da VBR, levado em consideração que o proprietário ao adquirir o referido engenho o fez com o intuito de poder melhor gerenciar a sua atividade e assim alavancar o seu volume de produção, fica claro que o evento dá resposta positiva à questão da organização proposta por Barney e Hesterly (2007).

Além disso, ao contratar os antigos moradores da propriedade, possuidores de conhecimentos sobre a atividade produtiva já aplicados no antigo engenho, o Senhor Armando buscou legitimar a sua decisão com base na Teoria Institucional pelo mecanismo do isomorfismo normativo (DIMAGGIO e POWELL, 2005), uma vez que houve pressão por parte daqueles moradores para que a empresa decidisse a respeito daquela situação.

\section{Evento crítico 8 - Novo Entrante e a Concorrência das Destilarias}

Pernambucanas (1988): A concorrência que havia antes deste período histórico nunca causou maiores preocupações aos gestores da empresa. Sendo assim, não havia uma preparação em relação ao surgimento de produtores que concorressem em pé de igualdade. Tal situação os levaram a uma aceitação passiva sem implementação de reações competitivas estratégicas à entrada de tais entrantes.

Como não houve reação estratégica por parte do Senhor Armando à entrada de novos concorrentes, também não se pôde identificar qualquer relação com as teorias da perspectiva Institucionalista ou da Visão baseada em Recursos, podendo-se considerar como inércia organizacional o fato de não ter dado resposta a esta força competitiva.

\subsubsection{A década de 90 - Crise e Adaptação à Crise}

Neste período, a Vargem Bela já trazia do final da década anterior a perda de clientes pelo surgimento de concorrentes de peso na região. Aliado a isto, no ano de 1993, o estado da Paraíba sofreu com uma grande estiagem, o que reduziu drasticamente a safra de cana-deaçúcar, tendo como consequência imediata a redução no volume da cachaça produzida. Vale dizer que acontecimentos como estes geram resultados que perduram às vezes por muito tempo.

Para adquirir a ferragem (destilaria) em 1979, a coluna de destilação em 1983 e o Engenho Varginha em 1986, a empresa precisou realizar empréstimos junto aos bancos que estavam cobrando tais dívidas. Segundo o relato de Armando Júnior, 
Antonio Rodrigues Neto \& Lucia Santana de Freitas

[...] era a época dos planos Collor e isso, aliado à redução na produção em virtude da seca, a perda de clientes para os novos concorrentes, e a cobrança dos empréstimos feitos aos bancos trouxe problemas muito sérios para a empresa, e papai teve que ceder parte do patrimônio para os bancos como pagamento das dívidas em 1997.

Evento crítico 9 - A Grande Estiagem (1993): A seca é um fenômeno climático que quando ocorre em determinada região afeta todas as organizações. No caso das empresas produtoras de cachaça, todas foram afetadas e tiveram como consequência imediata a redução na oferta de matéria-prima, o que impôs redução na quantidade produzida de cachaça.

O evento aqui analisado não possui características voluntaristas, o que não o relaciona com a teoria da Visão Baseada em Recursos. Entretanto, a ocorrência possui traços totalmente determinísticos, o que a vincula ao Isomorfismo Institucional, tendo havido aqui um processo de homogeneização que segundo DiMaggio e Powell (2005) ocorre quando “[...] a quantidade de formas organizacionais é determinada pela distribuição de recursos no ambiente e pela forma como esses recursos estão disponíveis". Não foi possível, entretanto, relacionar esta homogeneização, ou seja, isomorfismo, com qualquer uma das três formas proposta pelos autores.

Evento crítico 10 - Pagamento das Dívidas (1997): A empresa nesse período passou por crises resultantes dos planos Collor I e II que tiveram reflexo negativo no seu fluxo de caixa, fazendo acumular as dívidas oriundas dos empréstimos feitos junto aos bancos. Diante deste quadro e sem outra alternativa para saldar as dívidas junto às instituições financeiras, o Senhor Armando decidiu-se por negociação: ceder a estas, parte das terras do seu patrimônio como pagamento.

\subsubsection{A Primeira Década do Século XXI - A Produção de Cachaça Artesanal - 2003-2007}

No ano de 2003, o Senhor Armando Júnior percebeu que na Paraíba existe um mercado apreciador de Cachaça de Qualidade, além de haver também a produção desta bebida em alguns engenhos do estado. Conforme ele relata: “o momento é de transição. As pessoas já percebem o valor de uma boa cachaça e os bons restaurantes já têm o produto para oferecer como aperitivo. Antes as pessoas tinham vergonha de serem vistas degustando esta bebida”.

Para atender a demanda por este produto diferenciado, substituíram-se os resfriadores dos alambiques por novos, uma vez que os antigos já estavam saturados com zinabre; adaptou-se defragmadores, que permitiu uma melhor separação do álcool com a água; mudaram-se as dornas normalmente de madeira ou ferro por dornas de aço inoxidável, além 
Análise do processo de adaptação estratégica de uma empresa produtora de cachaça à luz da teoria institucional e da visão baseada em recursos

de ter passado a controlar mais rigorosamente os seguintes fatores: temperatura: $30^{\circ}$; brix $^{5}$ : $15^{\circ}$; tempo e destilação; refrigeração; limpeza; pH: entre 4,0 e 5,0 para controle da acidez; e controle de sais de cobre.

O novo produto adicionado ao core da empresa impactou positivamente no que se refere à lucratividade proporcionada pela cachaça, em aproximadamente $25 \%$.

No ano de 2005, a cachaça Maresia recebeu o registro do Ministério da Agricultura Pecuária e Abastecimento, o que propiciou a possibilidade de participação em qualquer tipo de evento, bem como a exposição e venda em qualquer lugar.

Nesse sentido, a cachaça Maresia teve participação nos seguintes eventos: Seminário "Agro negócio da Cachaça do Nordeste"; Feira do Empreendedor em 2007, no Parque do Povo, promovido pelo SEBRAE-PB; e mais importante, participação na barraca Cachaça da Paraíba, durante o "Maior São João do Mundo" em Campina Grande/PB, onde diversas marcas deste destilado produzido na Paraíba também foram expostas.

Sobre a participação no espaço 'Cachaça da Paraíba', Armando Júnior afirma que: “A participação neste evento representou uma ótima oportunidade para difundir o nosso produto principalmente divulgação da marca Maresia, considerando que é um produto relativamente novo no mercado, assim como o aumento das vendas".

Evento crítico 11 - A Criação da Cachaça Maresia: retirando o coração da cachaça: Na descrição histórica, é relatado que já havia outros produtores de cachaça de qualidade no estado, bem como estes já possuíam os equipamentos necessários ao processo produtivo da cachaça artesanal e realizavam controle de qualidade do produto.

A análise teórica desta ocorrência relaciona-se à Teoria Institucional por meio do mecanismo de isomorfismo mimético (DIMAGGIO e POWELL, 2005), uma vez que o Senhor Armando Júnior procurou assemelhar a sua produção a de outros produtores deste campo da indústria.

O evento tem relação também com a teoria da Visão Baseada em Recursos pela resposta positiva à questão do valor (BARNEY e HESTERLY, 2007), uma vez que a decisão de produzir um produto diferenciado teve como finalidade a exploração de uma oportunidade surgida no ambiente.

Evento crítico 12 - Registro da Cachaça Maresia Junto ao Ministério da Agricultura Pecuária e Abastecimento (2005): A criação de um produto de origem animal ou vegetal exige que este seja registrado junto ao Ministério da Agricultura Pecuária e REAd | Porto Alegre - Edição 71 - Nº 1 - janeiro/abril 2012 - p. 211-241 
Antonio Rodrigues Neto \& Lucia Santana de Freitas

Abastecimento, que no caso da cachaça, obriga que se atenda às exigências do Regulamento Técnico para Fixação dos Padrões de Identidade e Qualidade para Aguardente de Cana e para Cachaça, aprovado pela Instrução Normativa $n^{\circ} .13$ de 29 de junho de 2005 do referido ministério.

Ao solicitar e obter o registro da Cachaça Maresia junto ao MAPA a empresa atendeu a uma exigência governamental que traça padrões para a configuração do produto, o que relaciona esta adaptação à Teoria Institucional, mais especificamente pelo isomorfismo coercitivo (DIMAGGIO E POWELL, 2005).

$\mathrm{O}$ registro do produto junto ao MAPA alinha-se também com a teoria da Visão Baseada em Recursos ao dar resposta positiva à questão do valor, posto que esta ação possibilitou a exploração da marca em mercados que, sem o registro, não seria possível (Barney e Hesterly, 2007).

\section{Evento crítico 13 - Participação no Seminário “Agro negócio da Cachaça do} Nordeste" (2006): Este evento abordou temas sobre a atividade produtora de cachaça, desde discussões sobre variedades de cana-de-açúcar, processo de envelhecimento do produto, controles legais e busca de padrões de identidade além de estudos de viabilidade de inserção das empresas produtoras no mercado consumidor e do produto no mercado internacional.

Também foi discutida a possibilidade de criação de uma levedura própria para ser usada no processo de fermentação por todos os produtores do estado, o que daria à cachaça paraibana um DNA próprio, havendo ainda estudos sobre a inserção da cachaça da Paraíba no mercado internacional.

O recurso conhecimento pode, conforme o gerenciamento que a organização dá ao mesmo, vir a ser fonte de vantagem competitiva sustentável, segundo King et al (2002). Nesse sentido, a busca pelo conhecimento no evento em que havia muitos produtores que desenvolviam a mesma atividade, tem características relacionadas à Teoria Institucional através do isomorfismo mimético, uma vez que muitos outros competidores participantes também buscavam estas capacidades (DIMAGGIO E POWELL, 2005).

\section{Evento Crítico 14 - Participação na Feira do Empreendedor em 2007 no Parque} do Povo promovido pelo SEBRAE-PB: Este evento se mostra como uma vitrina onde são expostas as forças econômicas do Estado, aí incluído o agro-negócio. O evento, patrocinado pelo SEBRAE-PB, é uma fonte imensa de conhecimentos, na qual se aprende sobre “[...] abertura de empresas, gestão empresarial, alternativas de negócios, novos empreendimentos, 
Análise do processo de adaptação estratégica de uma empresa produtora de cachaça à luz da teoria institucional e da visão baseada em recursos

inovações tecnológicas, além de acesso a mercados e ao crédito" (SEBRAE-PB, 2007), além de contar com a exposição de produtos dos mais diversos segmentos da indústria paraibana.

Aqui também, como na ocorrência anterior, percebe-se uma busca pelo conhecimento, tanto no que se refere à atividade de produção de cachaça, como em relação à gestão empresarial, além de expor a marca a um público de aproximadamente 30.000 pessoas durante a sua duração. Diversos produtores de cachaça expuseram seus produtos na feira, buscando também o conhecimento. Portanto, o evento reveste-se de características do Isomorfismo Institucional através do isomorfismo mimético, posto que os competidores da empresa tiveram este mesmo tipo de comportamento.

\section{Evento crítico 15 - Participação na Barraca “Cachaça da Paraíba” durante o} “Maior São João do Mundo" (2007): A marca de um produto é, segundo Hitt et al (2003), um recurso intangível que proporciona junto ao cliente percepções como qualidade e confiabilidade. $\mathrm{O}$ fato de estar exposto durante trinta dias, em uma vitrina como é o São João de Campina Grande, que recebe pessoas de todos os lugares do país, segundo os proprietários, deu maior visibilidade à marca o que alavancou as vendas, inclusive para outros estados.

A análise desta ocorrência, à luz da Teoria Institucional, relaciona-a ao isomorfismo mimético, uma vez que a empresa 'imita' outros produtores que também expuseram seus produtos no mesmo espaço (DIMAGGIO E POWELL, 2005). Analisado à luz da VBR, este evento responde positivamente à questão do valor (BARNEY e HESTERLY, 2007) já que proporcionou, a partir daquele momento, explorar a oportunidade de venda do produto em outros estados, além de fortalecer a marca pela divulgação do mesmo.

\subsubsection{Síntese da Análise dos Eventos Críticos}

Visando proporcionar uma visão cronológica do processo de adaptação estratégica da empresa em estudo, ilustrou-se, de modo sintetizado no quadro 1, a análise dos eventos ocorridos durante cinco décadas estudadas. 
Antonio Rodrigues Neto \& Lucia Santana de Freitas

Quadro 1: Síntese da análise dos eventos críticos ocorridos no período de 1961 a 2007

\begin{tabular}{|c|c|c|c|}
\hline \multirow[t]{2}{*}{ ANO } & \multirow[t]{2}{*}{ EVENTO } & \multicolumn{2}{|c|}{ TEORIA } \\
\hline & & INSTITUCIONAL & VBR \\
\hline 1961 & $\begin{array}{l}\text { 1. Adoção de Cana-de-açúcar como } \\
\text { Matéria-prima de Produção de Cachaça }\end{array}$ & Isomorfismo mimético & Valor \\
\hline 1974 & $\begin{array}{l}\text { 2. Aquisição de Conhecimentos e } \\
\text { Competências. }\end{array}$ & & $\begin{array}{l}\text { Características tácitas; } \\
\text { Robustez; } \\
\text { Heterogeneidade; Limites } \\
\text { à competição ex-post; } \\
\text { Imperfeita Imitabilidade; e } \\
\text { valor. }\end{array}$ \\
\hline 1975 & 3. Aquisição de Terras & & Valor \\
\hline 1979 & 4. Aquisição de uma Destilaria & & Valor \\
\hline 1982 & $\begin{array}{l}\text { 5. A Legalização da Empresa Vargem Bela } \\
\text { Agroindustrial Ltda. }\end{array}$ & Isomorfismo coercitivo & Valor \\
\hline 1983 & 6. Aquisição de uma Coluna de Destilação & Isomorfismo mimético & Valor \\
\hline 1986 & 7. Aquisição do Engenho Varginha & Isomorfismo normativo & $\begin{array}{l}\text { Limites à competição ex- } \\
\text { post e Organização }\end{array}$ \\
\hline 1988 & 8.Surgimento de Forte Concorrência & $\begin{array}{l}\text { Não houve reação estraté } \\
\text { caracterizando-se assim, }\end{array}$ & $\begin{array}{l}\text { a por parte da empresa, } \\
\text { no inércia organizacional. }\end{array}$ \\
\hline 1993 & 9.Grande estiagem & Isomorfismo & \\
\hline 1997 & 10.Pagamento de Dívidas & Isomorfismo coercitivo & \\
\hline 2003 & $\begin{array}{l}\text { 11. A Criação da Cachaça Maresia: } \\
\text { retirando o coração da cachaça }\end{array}$ & Isomorfismo mimético & Valor \\
\hline 2005 & $\begin{array}{l}\text { 12. .Registro da Cachaça Maresia junto ao } \\
\text { Ministério da Agricultura Pecuária e } \\
\text { Abastecimento }\end{array}$ & Isomorfismo coercitivo & Valor \\
\hline 2006 & $\begin{array}{l}\text { 13. Participação no Seminário "Agro } \\
\text { negócio da Cachaça do Nordeste" }\end{array}$ & Isomorfismo mimético & \\
\hline 2007 & 14. Participação na Feira do Empreendedor & Isomorfismo mimético & \\
\hline 2007 & $\begin{array}{l}\text { 15. Participação na Barraca "Cachaça da } \\
\text { Paraíba" durante o "Maior São João do } \\
\text { Mundo" }\end{array}$ & Isomorfismo mimético & Valor \\
\hline
\end{tabular}

Fonte: Elaboração própria.

As informações apresentadas e analisadas vêm corroborar com as proposições da teoria institucional no que se refere à influência do ambiente sobre as organizações que, no caso deste estudo, mesmo havendo características da VBR junto as características isomórficas, a ação da empresa era apenas reativa às imposições ambientais: quando o ambiente impõe reações por pressões isomórficas, ainda que normativas ou coercitivas, é possível que estas agreguem valor à empresa, podendo isto ocorrer também em reações miméticas.

\section{CONSIDERAÇÕES FINAIS}

O processo de adaptação estratégica vivido pela empresa apresenta diferentes características em dois períodos temporais distintos sem que esses apresentem limites claramente definidos entre o término de um e o começo do outro, havendo, na verdade, uma 
Análise do processo de adaptação estratégica de uma empresa produtora de cachaça à luz da teoria institucional e da visão baseada em recursos

transição de um para o outro. No primeiro período, que vai de 1961 a 1986, o ambiente apresenta-se menos complexo e com poucas demandas à empresa, além disso a concorrência é incipiente e a empresa mantém liderança no mercado. Neste período, a postura assumida no processo de mudança foi mais proativa, em que aquisições foram realizadas por ativos tangíveis e intangíveis capazes de construir vantagens competitivas sustentáveis, tornando a empresa mais competitiva e líder de mercado.

Entretanto, no segundo período, que vai de 1986 a 2007, o ambiente começa a apresentar um maior nível de complexidade e novas pressões sobre a empresa. O aumento contínuo da concorrência, as pressões governamentais e de órgãos financiadores, a estiagem do início da década de 90, as vantagens competitivas adquiridas no primeiro período já não eram raras, uma vez que passaram a ser também utilizadas pelos competidores, entre outros, exerceram fortes pressões sobre a empresa. Neste período, a postura assumida por esta passa a ser mais reativa, em uma demonstração de inércia organizacional, passando a atuar no sentido de atender às pressões ambientais.

No caso estudado, pode-se perceber que o primeiro período é caracterizado pelo voluntarismo, ou seja, a organização através de suas ações consegue impor-se ao ambiente e influenciá-lo diante de baixas pressões ambientais. Consegue ainda focar em suas atividades internas, melhorando suas competências essenciais e construindo vantagens competitivas sustentáveis. Enquanto que o segundo período é caracterizado pelo determinismo ambiental, ou seja, fortes pressões ambientais sobre a empresa limitando-a a um comportamento apenas reativo, em grande parte utilizando-se do isomorfismo mimético.

Portanto, com base no caso estudado, pode-se inferir que voluntarismo e determinismo ambiental são dois lados de um continuum em que as organizações não ocupam uma posição fixa, ou seja, vão se aproximando de um lado ou de outro, dependendo do tipo de ambiente em que estão inseridas e da capacidade de resposta destas às demandas ambientais.

Por último, cabe destacar as contribuições, limitações e sugestões para pesquisas futuras. No que tange às contribuições, pode-se ressaltar a importância da realização de estudos sobre processo de adaptação estratégica, uma vez que tal processo é vivido por muitas organizações, principalmente quando estudados numa perspectiva longitudinal e embasados por mais de uma perspectiva teórica. Contribuem também como fonte de informações sobre o setor, dado a escassez de trabalhos científicos que contemplem tal setor. Quanto às limitações, apesar da riqueza de detalhes apresentados, as informações não são passíveis de 
Antonio Rodrigues Neto \& Lucia Santana de Freitas

generalizações por se tratarem de um estudo de caso. Por último, dá-se como sugestão para futuras pesquisas, a realização deste estudo nas demais empresas do setor no Estado da Paraíba assim como em outros Estados - procurando conhecer o processo de adaptação estratégica em nível setorial por estado ou região.

\section{REFERÊNCIAS}

ALBERNAZ, MURILO. Anotações para uma estratégia da cachaça de alambique [mensagem pessoal]. Mensagem recebida por <fenaca@ fenaca.org.br> em 05 nov. 2007.

ALPERSTEDT, GRAZIELA DIAS; MARTIGNAGO, GRACIELLA; FIATES, GABRIELA GONÇALVES SILVEIRA. O processo de adaptação estratégica de uma instituição de ensino superior sob a ótica da Teoria Institucional. Revista de Ciências da Administração, Florianópolis, v.8, n.15, jan/jun 2006.

BARNEY, J. B.; HERTERLY, W. S. Administração estratégica e vantagem competitiva. São Paulo: Pearson Prentice Hall, 2007.

CALDAS, MIGUEL P.; FACHIN, ROBERTO. Paradigma funcionalista: desenvolvimento de teorias e institucionalismo nos anos 1980 e 1990. Revista de Administração de Empresas, São Paulo,V. 45, nº 2, 2005.

CAVALCANTI, CARLOS. Cachaça da Paraíba ganha mercado e safra cresce $20 \%$. Jornal a União. Publicado em 08/02/2007. Disponível em $:<\mathrm{http}$ ///auniao.pb.gov.br/index.php?option=com_content\&task=view\&id=5330\& Itemid=44>. Acesso em: 05 nov. 2007.

COTA, PAULO ROBERTO DOS SANTOS. Gestão estratégicas de mudanças: estudo de caso numa empresa do setor elétrico. Congresso Virtual Brasileiro de Administração - 24 a 26 de novembro de 2006.

DIMAGGIO, Paul J; POWEL, Walter W. A Gaiola de ferro revisitada: isomorfismo institucional e racionalidade coletiva nos campos organizacionais. In: RAE Clássicos. Revista de Administração de Empresas. São Paulo, V.45, n 2, abr/jun, 2005. 
Análise do processo de adaptação estratégica de uma empresa produtora de cachaça à luz da teoria institucional e da visão baseada em recursos

FORMIGA, KATIÚSCIA. Paraíba investe R\$ 10 milhões em cachaça. Jornal Correio da Paraíba. Veiculado em 05/07/2007 Disponível em:

http://www.agencia.ufpb.br/ver.php?pk_noticia=2253>. Acesso em: 06 mar.2008.

GODOY, ARILDA SCHIMIDT. Introdução à pesquisa qualitativa e suas possibilidades. Revista de Administração de Empresas. São Paulo, v. 35, n. 2, p. 57-63, mar./abr. 1996.

HANNAN, M. T.; FREEMAN, J. The population ecology of organizations. American Journal Sociology, Chicago, V. 82, n. 5, p. 029-964, 1977.

HALL, PETER A.; TAYLOR, ROSEMARY C. R. As três versões do neo-institucionalismo. Lua Nova, Água Branca, n. 58, p. 193-224. 2003.

HITT, MICHAEL A.; IRELAND, R DUANE; HOSKSSON, ROBERT E. Administração estratégica: competitividade e globalização, São Paulo: Pioneira Thomsom Learning, 2003.

KING, ADELAIDE WILCOX; FOWLER, SALLY W.; ZETHHAML, CARL P. Competências organizacionais e vantagem competitiva: o desafio da gerência intermediária. Revista de Administração de Empresas. v. 42. n. 1 p. 36-49. Jan./Mar. 2002.

IBRAC, Instituto Brasileiro da Cachaça. Informações setoriais: produção nacional. Disponível em: <http://www.ibraccachacas.org/producao-nacional_3>. Acesso em: 24 out. 2007.

LIMA, JOÃO POLICARPO RODRIGUES. Cachaça artesanal e vinhos finos do nordeste: desafios, potencialidades e indicações de políticas. Revista Econômica do Nordeste. Fortaleza, V. 37 no 4, jul-set, p.609-627. 2006.

MINISTÉRIO DA AGRICULTURA, PECUÁRIA E ABASTECIMENTO (MAPA). O Setor Produtivo da Cachaça. Disponível em: <http://www.agricultura.gov.br>. Acesso em: 11 nov. 2007. 
Antonio Rodrigues Neto \& Lucia Santana de Freitas

MINISTÉRIO DA AGRICULTURA, PECUÁRIA E ABASTECIMENTO (MAPA).

Instrução Normativa $n^{\circ} 13$ de 29 de junho de 2005: regulamento técnico para fixação dos padrões de identidade e qualidade para aguardente de cana e para cachaça. In DOU $\mathrm{N}^{\mathbf{0}} 124$, de 30 de junho de 2005. Disponível em: < http://www.ampaq.com.br/leis/IN13.pdf>. Acesso em: 26 fev. 2008.

\section{MINISTÉRIO DO DESENVOLVIMENTO INDÚSTRIA E COMÉRCIO EXTERIOR} (MDIC). Consultas: exportação (1996 a 2008). Disponível em:

$<$ http://aliceweb.desenvolvimento.gov.br/default.asp>. Acesso em: 22 fev. 2008.

MONTEIRO, VALLADARES ANGELISE; CARDOSO, SHANDI PEREIRA. Adaptação estratégica e perspectivas teóricas e mudança em um centro de pesquisa do governo. Revista de Ciências da Administração. Florianópolis, V.4, n.08, jul/dez 2002.

NEVES, JOSÉ LUIS. Pesquisa qualitativa - Características, usos e possibilidades. Caderno de Pesquisa em Administração, São Paulo, V. 1, nº 3, 2 sem. 1996.

PATRIOTA, Fernando. Feira da cachaça. In: Jornal a União. Disponível em: $<$ http://www.auniao.pb.gov.br/v2/index.php?option=com_content\&task=view\&id=2345\&Ite mid=1> 2006. Acesso em: 06 mar. 2008.

PENROSE, EDITH. Teoria do crescimento da firma. Tradução: Tamás Szmrecsányi. Campinas, SP, Editora da Unicamp, 2006.

PETERAF, MARGARETH A. The Cornerstones of competitive Advantage: A Resourcebased view. Strategic Management Journal. V. 14, p. 179-191. 1993.

PETTIGREW, ANDREW. M. Context and action in the transformation of the firm. Journal of Management Studies, v. 24, n. 6, p. 649-670, 1987.

ROSSETTO, CARLOS RICARDO; CUNHA, CRISTIANO J.C. de A; ORSSATO, HENRIQUE CARLOS; MARTIGNAGO, GRACIELLA. Os elementos da mudança 
Análise do processo de adaptação estratégica de uma empresa produtora de cachaça à luz da teoria institucional e da visão baseada em recursos

estratégica empresarial: um Estudo exploratório. Revista Teoria e Evidência Econômica. Passo Fundo, v.4, n.7/8, p.111-120, maio/nov. 1996.

SANCHEZ, R.; HEENE, A.; THOMAS, H. Dynamics of competence-based competition: theory and practice in the new strategic management. Oxford : Pergamon, 1996.

SERRALHEIRO, WERTHER ALEXANDRE DE OLIVEIRA. O processo de adaptação estratégica das empresas Eliane sob a Ótica da Teoria Institucional e da Visão Baseada em Recursos (RBV). 154 f. Dissertação DE Mestrado em Engenharia da Produção, Universidade Federal de Santa Catarina, Florianópolis, 2004

SERVIÇO BRASILEIRO DE RESPOSTAS TÉCNICAS. Rede de Tecnologia.

Biotecnologia: pé-de-cuba, formulação, cachaça. Disponível em:

http://sbrtv1.ibict.br/upload/sbrt634.pdf>. Acesso em: 11 fev. 2008.

SILVA, LEONARDO HENRIQUE DE ALMEIDA; ROCHA, LUIZ EDUARDO DE VASCONCELOS; LIMA, IVIS BENTO; SANTOS, GILNEI COSTA. Cachaça de minas e desenvolvimento rural: uma análise do cooperativismo como impulso para o agronegócio. Disponível em: http://www.agencia.cnptia.embrapa.br/gestor/cana-deacucar/catalogo/REC000fjd717w802wyiv809gkz518a6lhvf.html, Acesso em: 12 nov. 2007.

TEECE, D. J.; PISANO, GARY; SHUEN, AMY. Dynamic capabilities and strategic management. Strategic Management Journal, v. 18, n. 7, p. 509-533, Aug. 1997.

UNB, Serviço Brasileiro de Respostas Técnicas. Brix. Disponível em: $<$ http://sbrtv1.ibict.br/upload/sbrt7225.pdf> Acesso em: 11 fev. 2008.

VERDI, ADRIANA RENATA. Dinâmicas e perspectivas do mercado da cachaça. Informações Econômicas, São Paulo, v. 36, n. 2, fev. p. 93-98, 2006.

WERNERFELT, BIRGER. A Resource-Based View of the firm. Strategic Management Journal. V.5, p. 171-180.1984. 


\section{Antonio Rodrigues Neto \& Lucia Santana de Freitas}

YIN, R. K. Estudo de caso: planejamento e métodos. Porto Alegre, Bookman, 2001.

\footnotetext{
${ }^{1}$ Cachaça é a denominação típica e exclusiva da aguardente de cana produzida no Brasil, com graduação alcoólica entre trinta a quarenta e oito por cento em volume, a vinte graus Celsius, obtida pela destilação do mosto fermentado de cana-de-açúcar com características sensoriais peculiares, podendo ser adicionada de açúcares até seis gramas por litro, expressos em sacarose. (Decreto n. 4.851, de 02/10/2003, Artigo 92).

2 Além de cachaça de alambique, este produto também recebe as denominações de: cachaça de qualidade e cachaça artesanal, valendo dizer aqui que este produto é processado apenas em alambiques. Ao longo do trabalho serão utilizados mais de um termo.

3 Engenheiro Industrial, na modalidade de química, professor da Escola Politécnica da USP e chefe do Departamento de Engenharia Química da mesma Universidade, de março de 1987 a março de 1991.

${ }^{4}$ Pé de cuba é o fermento iniciador do processo de fermentação do mosto (caldo) de cana, através da levedura Saccharomyces cerevisiae, fungo altamente adaptado ao álcool. O resultado da fermentação é a garapa fermentada ou mosto fermentado, o qual segue para os alambiques para o processo de destilação e transformação em cachaça (SBRT, 2008).

${ }^{5}$ Brix é considerado basicamente como a porcentagem de açúcar presente no suco. Para se referir ao Brix, utiliza-se o termo "graus Brix", o que equivale a uma porcentagem (UNB, SBRT).
} 